Gut, 1988, 29, 746-751

Liver and biliary

\title{
Laserlithotripsy of common bile duct stones
}

\author{
Ch Ell, G LUX, J HOCHBERGER, D MÜller, AND L DEMLing \\ From the Medizinische Klinik mit Poliklinik der Universität Erlangen-Nürnberg, Erlangen, FRG
}

SUMmary Endoscopic retrograde laser lithotripsy of common bile duct stones is a new technique which can be carried out through the endoscope without anaesthesia using ordinary endoscopic equipment. In the method described here a flashlamp pulsed Neodymium YAG laser (wave length $1064 \mathrm{~nm}$ ) was used. Light energy was transmitted along a highly flexible quartz fibre with a diameter of $0.2 \mathrm{~mm}$. This new technique was used in nine patients with concrements in the common bile duct, which could not be removed with the established endoscopic techniques. In eight of the nine the concrements (maximum diameter $4.7 \times 3.1 \mathrm{~cm}$ ) could be fragmented and in six the fragments could be extracted from the common bile duct. The total energy required was 80-300 J; complications were not observed.

Since the introduction of endoscopic papillotomy': and the extension of the method by the addition of mechanical lithotripsy, ${ }^{3}$ the endoscopic removal of bile duct stones has become a generally accepted therapeutic technique especially in aged patients or in those carrying an increased surgical risk. About $90 \%$ of all bile duct stones can be removed, on the rectrograde way through the endoscope. Very hard stones or concrements impacted in the coledochus, however, cannot be removed by this method and require surgery.

Address for correspondence: Priv Doz Dr med Christian Ell. Medizinische Universitätsklinik, Krankenhausstra13e 12. D-8520 Erlangen. Federal Republic of Germany.

Received for publication 3 December 1987
Alternative developments such as electrohydraulic lithotripsy, ${ }^{+}$ultrasound lithotripsy, ${ }^{5}$ or chemical dissolution of bile duct stones" have not been able to close the remaining endoscopic therapeutic gap. Extracorporeal shock wave lithotripsy is a successful method, although expensive, and requires general anaesthesia and a number of endoscopic preliminary and follow up examinations. ${ }^{7}$ Laser lithotripsy of stones in the common bile duct is a new method which can be done with the endoscope, retrograde, without anaesthesia, by means of ordinary endoscopic equipment.

This study is an account of the preliminary experience gained in a total of nine patients treated by this method.

Table Clinical characteristics, techniques and results in nine laser treated patients with large common bile duct stones

\begin{tabular}{|c|c|c|c|c|c|c|c|c|}
\hline Patients & Sex & Age & Concomitant disease & $\begin{array}{l}\text { Stones } \\
(n)\end{array}$ & $\begin{array}{l}\text { Max } \\
\text { diameter } \\
\text { (cm) }\end{array}$ & Technique & Result: & Comment \\
\hline $1 \mathrm{HH}$ & $\mathrm{F}$ & 72 & Pancreatic cancer & 2 & $2 \cdot 2 \times 1.5$ & X-ray controlled/laser basket & + & \\
\hline $2 \mathrm{KK}$ & $\mathrm{F}$ & 77 & Liver cirrhosis & 4 & $4.7 \times 3 \cdot 1$ & Under direct vision & + & \\
\hline $3 \mathrm{TM}$ & $\mathrm{F}$ & 76 & - & 1 & $3 \cdot 6 \times 3 \cdot 1$ & $\mathrm{X}$-ray controlled/laser basket & $(+)$ & $\begin{array}{l}\text { Fragments not extractable } \rightarrow \\
\text { surgery }\end{array}$ \\
\hline $4 \mathrm{KC}$ & $\mathrm{F}$ & 77 & - & 1 & $4.3 \times 3.7$ & Under direct vision & + & \\
\hline $5 \mathrm{BM}$ & $\mathrm{F}$ & 68 & Chronic lymphatic leukemia & 7 & $2 \cdot 9 \times 2 \cdot 3$ & $\mathrm{X}$-ray controlled/laser basket & $(+)$ & $\begin{array}{l}\text { Fragments not extractable } \rightarrow \\
\text { internal drainage }\end{array}$ \\
\hline $6 \mathrm{~K}-\mathrm{WM}$ & $\mathrm{F}$ & 68 & Liver cirrhosis & 2 & $3 \cdot 8 \times 2 \cdot 8$ & $\begin{array}{l}\text { Laser-balloon/X-ray } \\
\text { controlled }\end{array}$ & + & \\
\hline $7 \mathrm{KJ}$ & $\mathbf{M}$ & 85 & $\begin{array}{l}\text { Heart failure arrhythmias } \\
\text { (Lown IV) }\end{array}$ & 2 & $4.5 \times 2 \cdot 8$ & $\mathrm{X}$-ray controlled/laser basket & + & \\
\hline $8 \mathrm{SG}$ & M & 62 & - & 1 & $2 \cdot 6 \times 2 \cdot 0$ & $\mathrm{X}$-ray controlled/laser basket & + & \\
\hline $9 \mathrm{AM}$ & $\mathbf{F}$ & 76 & Liver cirrhosis & 1 & $4.5 \times 4 \cdot 0$ & $\mathrm{X}$-ray controlled/laser balloon & - & $\begin{array}{l}\text { Extracorporeal shock wave } \\
\text { lithotripsy followed }\end{array}$ \\
\hline
\end{tabular}




\section{Method}

Laser lithotripsy was carried out with a flashlamp pulsed Nd:YAG laser (wave length $1064 \mathrm{~nm}$ ) (by LASAG, Thun, Switzerland). The following parameters are freely adjustable: pulse frequency (1-20) $\mathrm{Hz}$ ), pulse energy $(0 \cdot 1-4 \mathrm{~J})$, and pulse duration $(0 \cdot 1-10 \mathrm{msec})$. The laser energy is transmitted through a highly flexible quartz fibre with a diameter of $(0.2 \mathrm{~mm}$. The stones are fragmented by leading the quartz fibre with low energy pulses from the surface to the centre of the stone and consecutive augmentation of the pulse energy.

\section{PATIENTS}

Up to the present nine patients all over 60 years have been treated with one or several bile duct stones using laser lithotripsy. Some had presented with severe concomitant diseases (Table). Laser lithotripsy was only done when the use of the other techniques (removal with the dormia basket, mechanical lithotripsy) was not possible or had failed. Before the treatment the patients were told about the potential dangers and risks of the new method and about the existing surgical alternatives. After two days consideration the patients agreed to the treatment in writing. Premedication was the same used for diagnostic ERCP and consisted of 10-20 mg diazepam iv 2-4 $\mathrm{ml}$ butyl-scopolamine iv and, in individual cases, $1 \mathrm{ml}$ pethidine iv. The patients were checked afterwards for 48 hours and the following parameters were controlled every six to 24 hours: rectal temperature, leucocytes, amylase, gamma GT, alkaline phosphatase, bilirubin, blood pressure, and pulse.

\section{TECHNIQUE}

When the papilla was intact, endoscopic papillotomy was carried out first. When laser lithotripsy was indicated, it was done two or three days after the papillotomy or procedures such as mechanical lithotripsy. Apart from an Olympus-Mother-Babyscope (prototype) we used the following conventional endoscopes: Olympus JF-3,7, Olympus TJF 10 , Pentax FD $34 \mathrm{H}$.

Depending on the anatomical situation, laser lithotripsy was done under direct endoscopic vision (two patients) or under $x$-ray control with a specially developed laser lithotriptor basket (five patients) or a balloon catheter (two patients) (Fig. 1). The centering of the light guide in the basket or in the balloon catheter ensured that the safety distance between light guide end and bile duct wall was always sufficiently great. The outer diameter of the basket litotriptor is, at present, $3.2 \mathrm{~mm}$, of the balloon catheter $1.8 \mathrm{~mm}$.

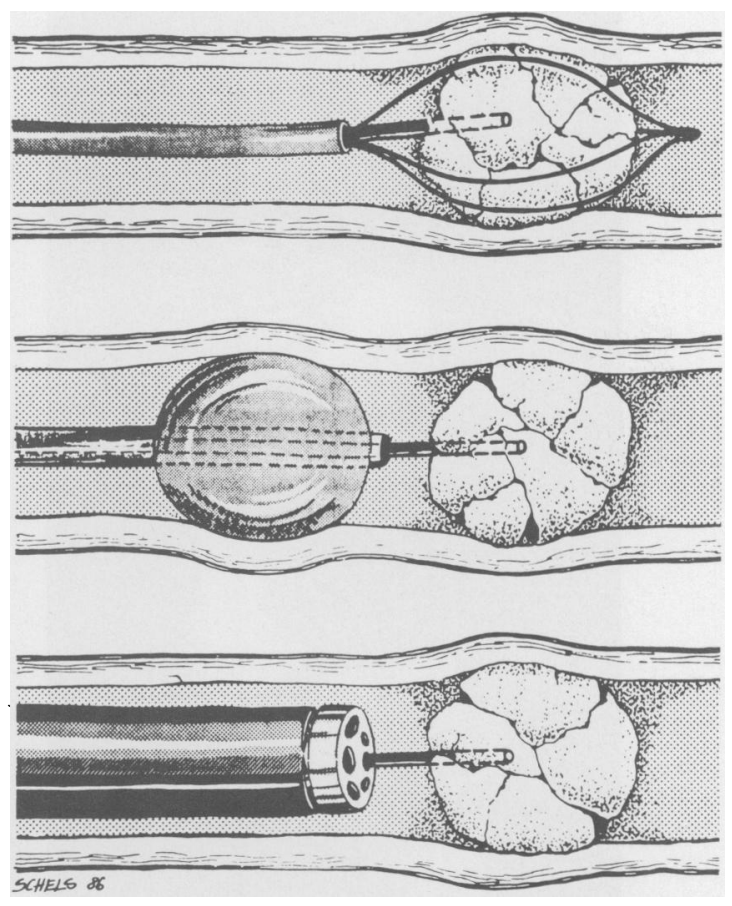

Fig. 1 Variation of the endoscopic techniques used: lithotripsy under $x$-ray control by means of the lithotriptorbasket or the balloon catheter; lithotripsy under direct endoscopic vision.

\section{Results}

Laser lithotripsy was successful in six of the nine patients: the concrements could be destroyed and removed endoscopically from the bile duct. In two patients only a partial success could be achieved: The stones could be destroyed, but the fragments could not be removed as they were impacted in the bile duct. Therefore, patient 3 had surgery without complications, patient 5 was given internal bile

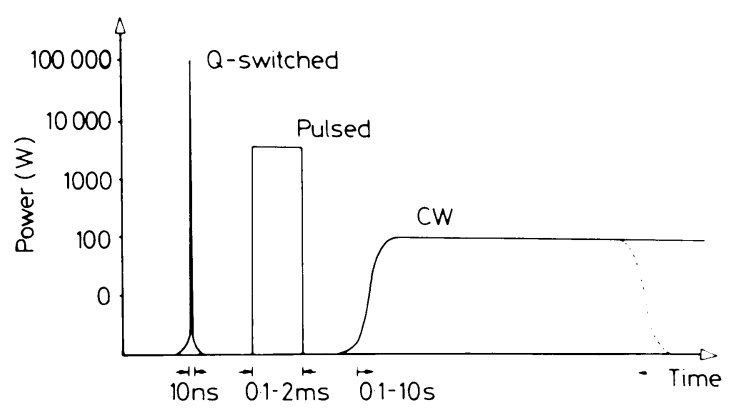

Fig. 2 Power energy relationship in pulsed and continuous wave laser systems. 


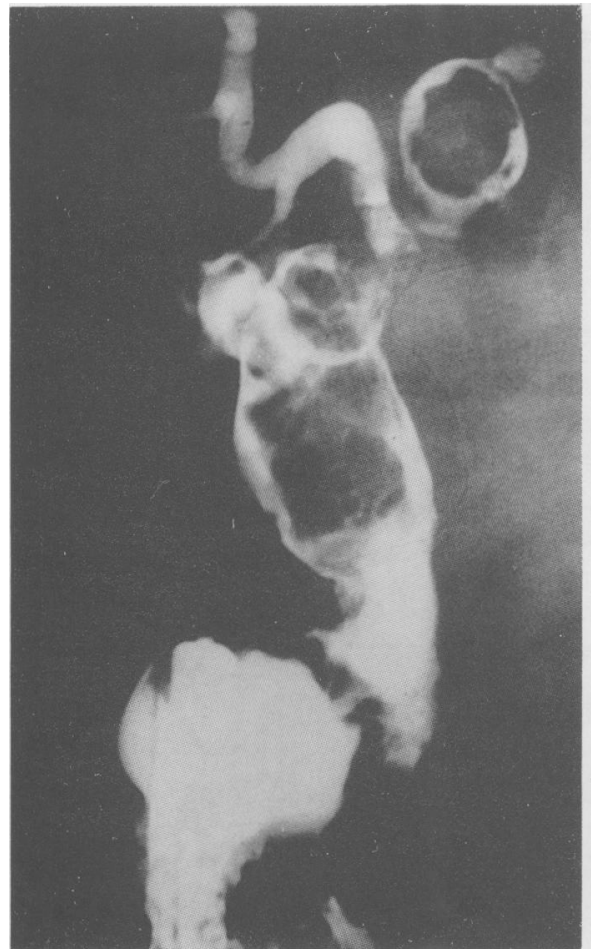

Fig. 3

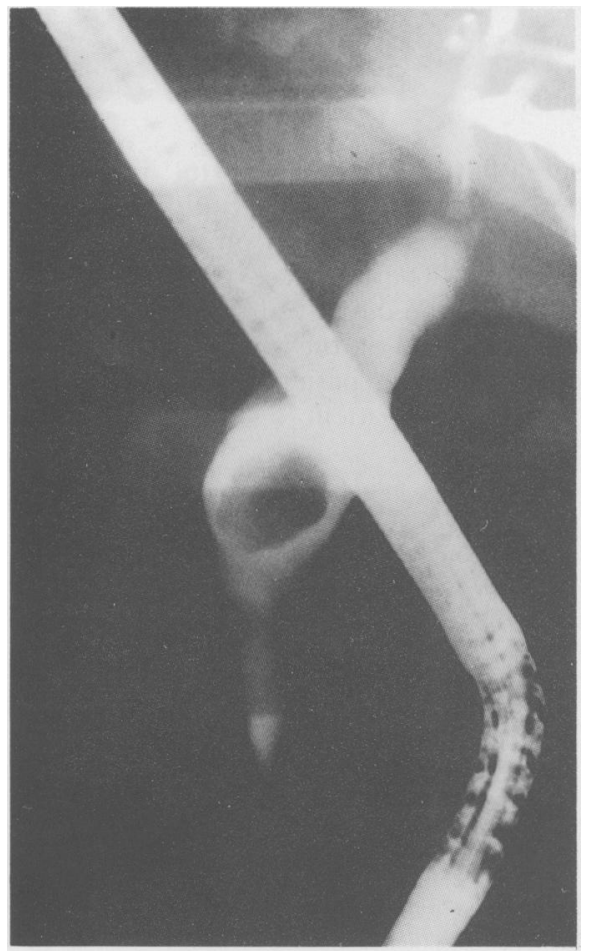

Fig. 5

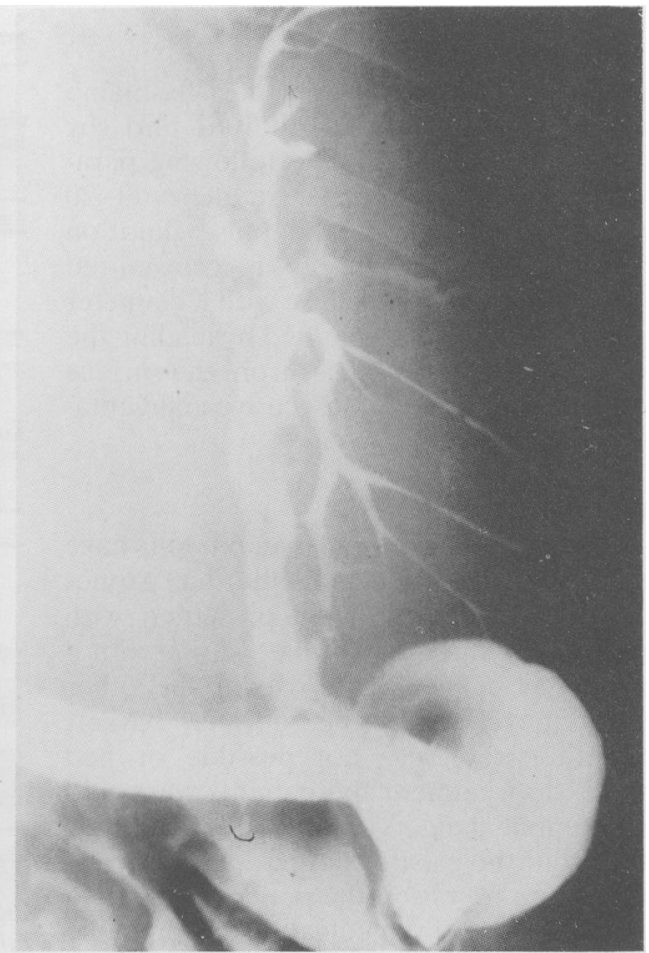

Fig. 4

Figs 3 and 4 Laser lithotripsy under direct endoscopic vision; before and after therapy (max stone diameter $4.3 \mathrm{~cm}$ ).

Figs 5 and $6 \quad X$-ray controlled laserlithotripsy by means of $a$ lithotriptor basket; after laser application a sharp fracture line can be seen (max stone diameter $2 \mathrm{~cm}$ ).

Figs 7,8 and $9 \quad X$-ray controlled laserlithotripsy by means of a balloon catheter system with a central channel for the fibre; before, during and after lithotripsy (max stone diameter $3.8 \mathrm{~cm}$ ).

$\stackrel{9}{\mathrm{C}}$ 


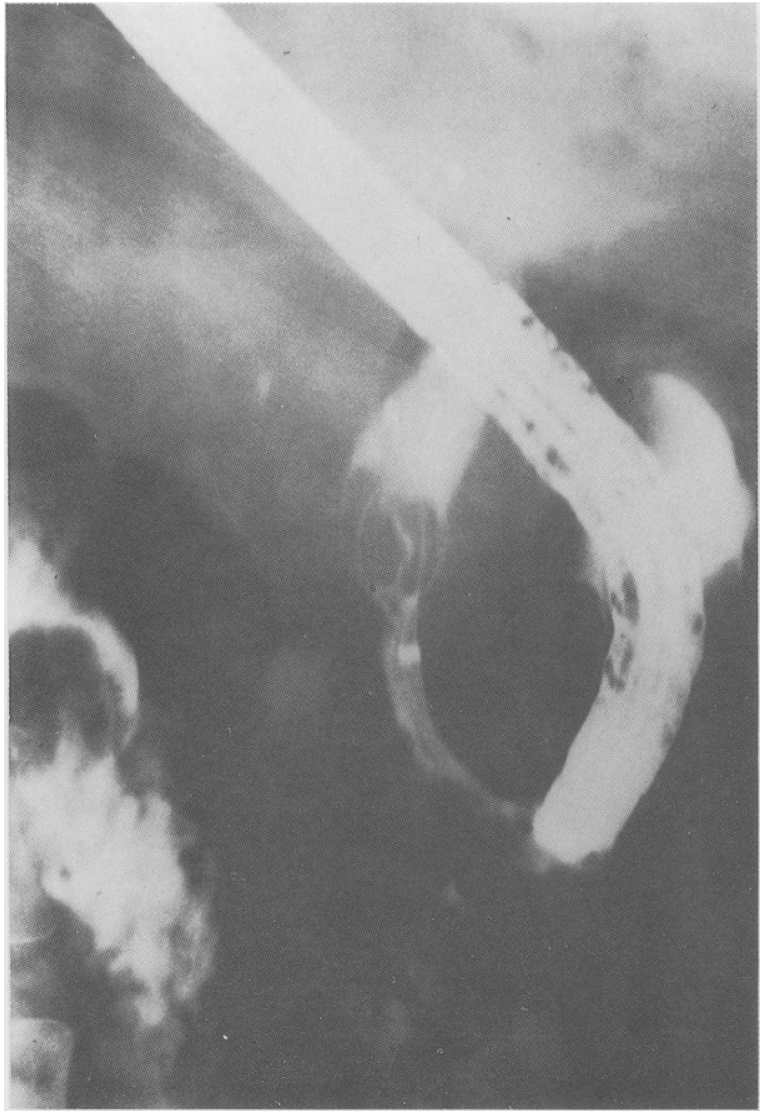

Fig. 6

drainage because of his poor state of health. In one patient lithotripsy was unsuccessful, although an adequate amount of energy was applied. For religious reasons this patient refused blood transfusions and therefore extracorporeal shock wave lithotripsy resulting in partial stone fragmentation.

In every case between 40 and 150 pulses $(80-300 \mathrm{~J})$ were necessary for lithotripsy. A repetition frequency fo $4 \mathrm{~Hz}$, an impulse duration of $1-2 \mathrm{msec}$ and an impulse energy of $1.5(0.5-2 \cdot 5) \mathrm{J}$ per pulse have proved to be favourable working parameters. No complications or pathological changes in the laser lithotripsy were observed neither during the acute follow up nor during the longterm follow-up period now lasting three to nine months.

\section{Discussion}

First reports on the fragmentation of gall stones with laser came from Japan. Orii et al reported lithotomies of bile duct concrements by means of a continuous wave $\mathrm{Nd}$ :YAG laser which is used in general tumour

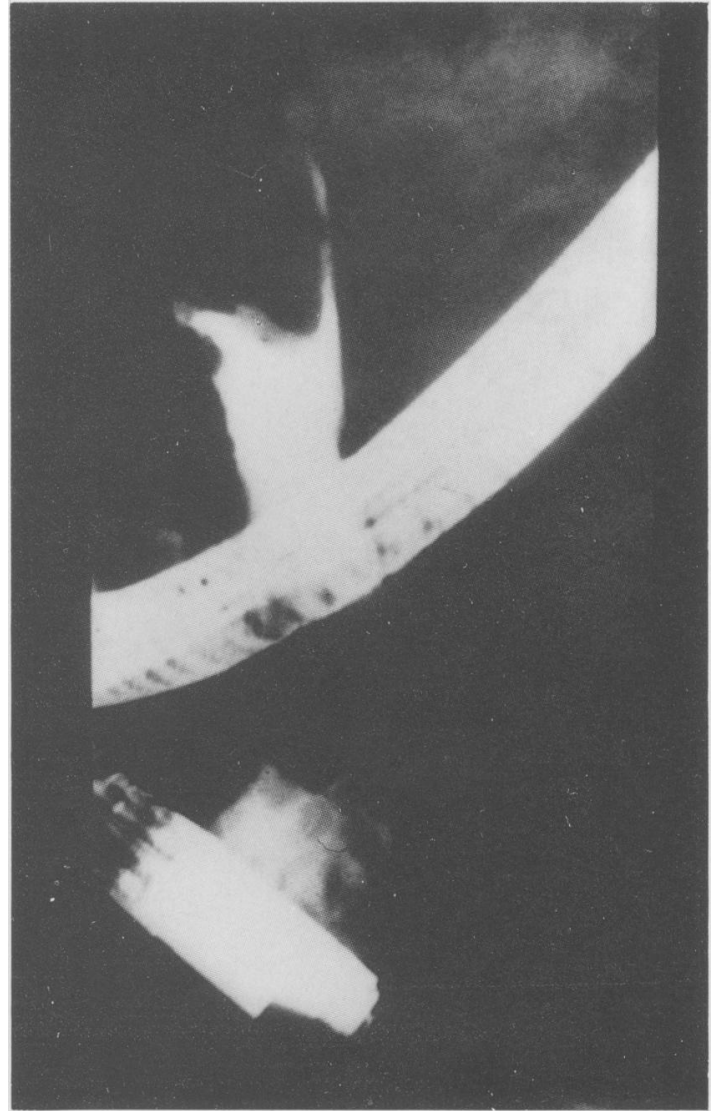

Fig. 7

therapy and haemostasis. ${ }^{89}$ The access to the bile duct system was transcutaneous-transhepatic. The fragmentation was done under choledochoscopic vision. Our own in vitro tests, however, in more than 80 gall stones showed that no lithotriptic but only thermal melting and drilling effects could be achieved with the continuous wave laser $(5-110 \mathrm{~W}, 0 \cdot 1-10$ sec). In addition, the $\mathrm{CW}$ laser continuously emits laser power over a relatively long period (within the second range) which results in the application of a high amount of total energy and produces danger of thermal injuries to the surrounding tissue.

In pulsed laser systems the risk of any damage to the surrounding tissue is reduced: the power peaks may reach more than $1,000,000$ Watts, but the power is only applied for fractions of a second $\left(10^{3}-10^{4}\right.$ sec). The applied total energy per pulse - the product of power and pulse duration - therefore only ranges between $10^{-3}$ to $10^{1} \mathrm{~J}$ (Fig. 2).

With a flashlamp pulsed Nd:YAG laser (see Methods) we were able to fragment gall stones in vitro reliably and reproducibly. ${ }^{\text {IN }}$ The fragmentation 


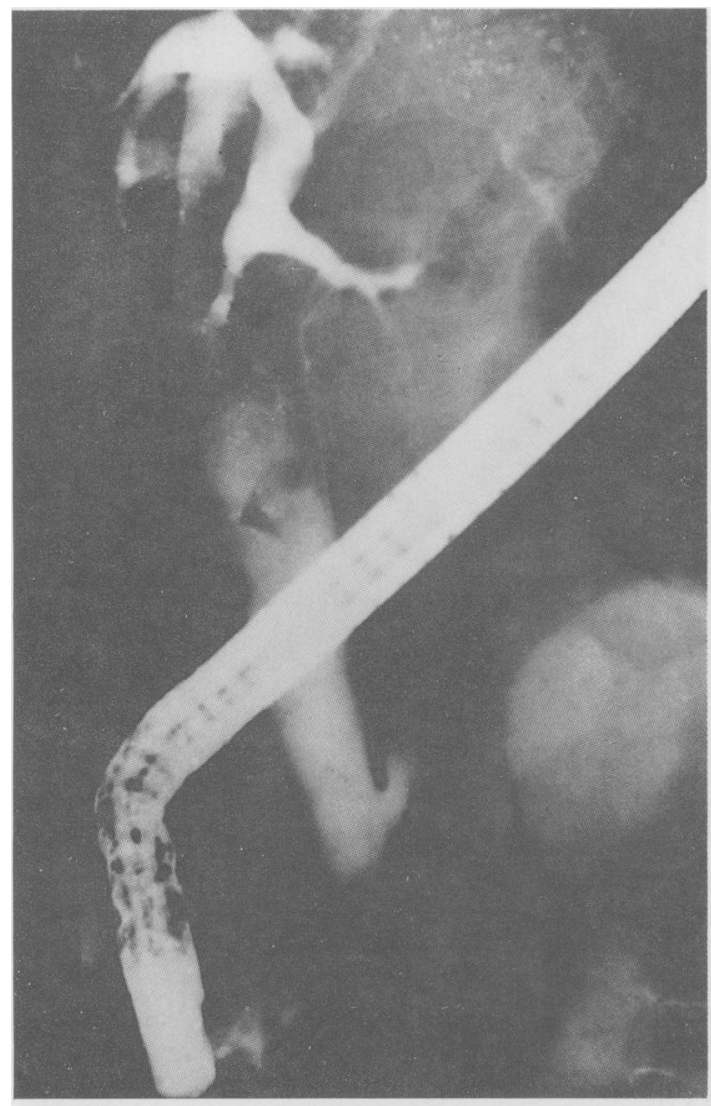

Fig. 8

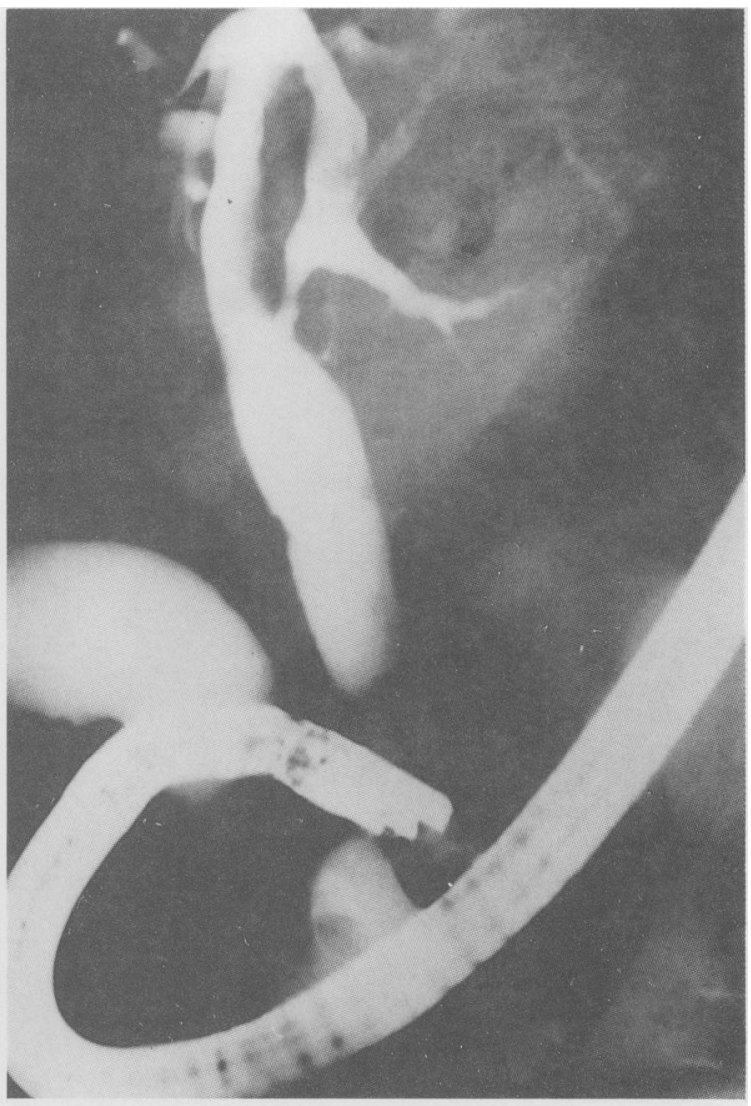

Fig. 9 process is of a thermal nature and can be explained by a very localised high vaporisation pressure in the stone centre. For the in vivo use through the endoscope a sufficiently flexible transmission system is necessary, which is available in the form of a highly flexible, $0.2 \mathrm{~mm}$ thin quartz fibre. Mechanical damage of the fibre is not to be feared even in a radius of curvature down to $5 \mathrm{~mm}$, transmission losses in extreme radii only amount to $15 \%$.

In acute animal experiments implanted human gall stones could be destroyed in 16 of 18 cases."' In chronic animal experiments in eight dogs it could be shown by laboratory tests, radiographs, and histological serial sections that even the direct pulsed laser irradiation of the bile duct wall does not cause any acute (cholangitis, peritonitis) or chronic (stenoses) complications (unpublished data).

No complications occurred in the first nine applications in man. In two patients with choledochoduodenostomy lithotripsy was possible under direct endoscopic vision (Figs 3 and 4). Risks for the surrounding structures can be excluded in such a procedure. At present, however, the choledochus may be inspected endoscopically only in rare cases. In most of the patients laser lithotripsy was therefore performed under $x$-ray control. There remains a risk, however, which cannot be totally excluded, that the bile duct is irradiated by mistake. In these cases a specially developed laser lithotriptor basket and its balloon modification contribute to the safety of the technique as the fibre is centrally guided in the catheter and the exact feed length of the fibre into the stone can be determined extracorporeally (Figs 1 , $5,6)$. The balloon modification is used if the stone is impacted or cannot be caught in the basket (Figs 7 , $8,9)$.

In eight of nine patients the concrements could be smashed. Possible reasons for the unsuccessful lithotripsy in patient 9 are a disturbance in the laser system (a control system of the power output at the distal end of the fibre during the treatment does still not exist), an unsufficient contact between the fibre and the 
stone or a special quality of the concrement - for example, a pure pigmented stone. In two patients the fragments could not be extracted through the endoscope as they were impacted in the bile duct. The reason for this is that the present Nd:YAG laser can only smash the gall stones into several larger particles. This can be improved by further developing the socalled Quality switched Nd:YAG laser and the pulsed dye laser. With these two systems it is possible in vitro to smash the gall stones into particles of only millimeters which then can be discharged through the papilla or can be easily removed." 12 With the Q-switched Nd:YAG laser the fragmentation is done mechanically by transforming light energy into a local shock-wave, the socalled optical breakdown. In the case of the dye laser with a wave length in the range of $450-700 \mathrm{~nm}$ the mechanism discussed is of thermal or mechanical nature. ${ }^{13}$ The reduced or absent danger of thermal damage constitutes future advantages of the dye laser and the Q-switched laser.

While fibres of $0.2 \mathrm{~mm}$ can be used in a dye laser and a flashlamp pulsed laser which allows the endoscopic retrograde method, the Q-switched laser still needs a fibre diameter of $0.6 \mathrm{~mm}$. The retrograde use of the Q-switched system is therefore not possible as the fibre is too rigid bearing the risk of mechanical break in the smallest radius of curvature (Alberan lever).

The first successful applications of endoscopic retrograde laser lithotripsy of bile duct stones in man described here mark the beginning of a new endoscopic technique. Further developments of the laser systems and improvements of the endoscopic equipment will open up the possibility for laser lithotripsy to become an economical, efficient, and safe endoscopic technique, and thus complement the nonsurgical treatment methods of bile duct stones.

\section{References}

1 Classen M, Demling L. Endoskopische Sphinkterotomie der Papilla Vateri und Steinextraktion aus dem Ductus choledochus. Dtsch Med Wochenschr 1974; 99: 496.

2 Demling L. Operative Endoskopie. Med Welt 1973; 24: 1253.

3 Demling L, Seuberth K, Riemann JF. A mechanical lithotriptor. Endoscopy 1982; 14: 100.

4 Koch H, Rösch W, Walz V. Endoscopic lithotripsy in the bile duct. Gastrointest. Endoscopy 1980; 26: 16.

5 Demling L, Ermert H, Riemann JF, Schmolke J, Heyder N. Lithotripsy in the common bile duct using ultrasound. Endoscopy 1984; 15: 226.

6 Allen MJ, Borody TJ, Bugliosi GR, May NF, LaRusso NF, Thistle JL. Rapid dissolution of gallstones by methyl tert-butyl ether. N Engl J Med 1985;312: 217-20.

7 Saucerbruch T, Delius M, Paumgartner G, et al. Fragmentation of gallstones by extracorporeal shock waves. $N$ Engl J Med 1986; 314: 818.

8 Orii K, Nakahara A, Takase Y, Ozaki A, Sakita T, Iwasaki Y. Choledocholithotomy by YAG laser with a choledochofiberscope; case reports of two patients. Surgery 1981; 90: 120.

9 Orii K, Ozaki A, Takase Y, Iwasaki Y. Lithotomy of intrahepatic and choledochal stones with YAG-laser. Surg Gynecol Obstet 1983; 156: 485.

10 Ell Ch, Hochberger J, Müller D, et al. Laserlithotripsy of gallstone by means of a pulsed neodymium YAGlaser in in vitro and animal experiments. Eñdoscopy 1986; 18 : 92.

11 Ell Ch, Wondrazek F, Frank F, Hochberger J, Lux G, Demling L. Laser-induced Shockwave Lithotripsy of gallstones. Endoscopy 1986; 18: 95.

12 Nishioka NS, Levins PC, Murray SC, Parrish JA, Anderson RR. Fragmentation of biliary calculi with tunable dye laser. Gastroenterology 1987; 93: 250.

13 Nishioka NS, Teng P, Deutsch TF, Anderson R. Mechanism of Laser-Induced Fragmentation of Urinary and Biliary Calculi. Lasers Life Sci 1987 (In press). 